\title{
Antenna effects and improved efficiency in multiple heterojunction photovoltaic cells based on pentacene, zinc phthalocyanine, and $\mathbf{C}_{60}$
}

\author{
Z. R. Hong, ${ }^{\text {a) }}$ R. Lessmann, B. Maennig, Q. Huang, K. Harada, M. Riede, and K. Leo ${ }^{\text {b) }}$ \\ Institut für Angewandte Photophysik (IAPP), Technische Universität Dresden, \\ 01062 Dresden, Germany
}

(Received 2 April 2009; accepted 30 June 2009; published online 25 September 2009)

\begin{abstract}
For organic solar cells, effective absorption over a wide wavelength range is important. A simple donor-acceptor pair is usually not sufficient to reach this goal. Thus, it would be desirable to utilize multiple photoactive materials in a single cell. In this work, two hole conducting materials, pentacene and zinc phthalocyanine $(\mathrm{ZnPc})$, and electron conducting $\mathrm{C}_{60}$ are chosen to construct three-component heterojunctions aiming at improved effective photon harvesting in organic solar cells. It is found that in pentacene $/ \mathrm{ZnPc} / \mathrm{C}_{60}$ multiple heterojunctions, part of the excitons in pentacene reach the $\mathrm{ZnPc} / \mathrm{C}_{60}$ interface, where efficient exciton separation occurs and contributes to the photocurrent (PC). Triplet excitons are confirmed to be the major origin of PC by transient PC response measurements, suggesting that triplet-to-triplet energy transfer from pentacene to $\mathrm{ZnPc}$ is responsible for the improved $\mathrm{PC}$ of pentacene $/ \mathrm{ZnPc} / \mathrm{C}_{60}$ multiheterojunctions. Furthermore, exothermic energy transfer from $\mathrm{ZnPc}$ to the lower lying triplet levels of pentacene is employed for extending the absorption range and enlarging the absorption intensity. To realize such a structure, an ultrathin $\mathrm{ZnPc}$ layer is embedded in the pentacene film in pentacene $/ \mathrm{C}_{60}$ single heterojunctions, leading to an enhanced quantum efficiency in the long wavelength range compared to the reference cell. These findings pave a way to efficient photovoltaic cells with a wide photoresponse ranging from near UV through the visible to the near infrared. (c) 2009 American Institute of Physics. [doi:10.1063/1.3187904]
\end{abstract}

\section{INTRODUCTION}

Organic solar cells have a unique potential of providing cost-effective energy resources, and thus have become more and more attractive in the past two decades. In contrast to their inorganic counterparts, the large exciton binding energy in organic matrices has to be overcome by separation at a donor-acceptor (DA) heterojunction, ${ }^{1}$ providing enough energy offset to overcome the Coulombic force between an electron-hole pair. The DA concept is, therefore, a major cornerstone of organic photovoltaic (PV). ${ }^{2}$ On the other hand, organic thin films normally have a single main absorption band with a width of $\sim 100 \mathrm{~nm}$ in the wavelength range of $400-900 \mathrm{~nm}$. The drawback is that it is difficult to design a DA pair, which covers the whole spectral range with only two compounds in a single heterojunction. Stacked tandem of triple cells combining many more photoactive materials in the different cells are therefore a promising design for effective absorption. ${ }^{3}$

As an alternative for efficient photon harvesting, inter- or intralayer cascaded energy transfer has been proposed by Koeppe et $a l^{4}$ and realized by Liu et al. ${ }^{5}$ The possibility to apply this method for polymer PV cells, however, is limited by the subtle balance of hole and electron mobilities in the bulk heterojunctions, which is difficult to control in the presence of the third absorbing component. Besides, for the best electron acceptors known for organic PV cells, $\mathrm{C}_{60}$ and its derivatives, the main absorption bands in blue regime insuf-

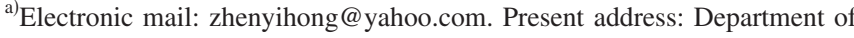
Materials Science and Engineering, University of California, Los Angeles. b) Electronic mail: karl.leo@iapp.de.
}

ficiently overlap with AM 1.5 solar spectrum. As a result, it is common to screen electron donor materials of better spectral match with AM 1.5, rather than acceptors.

In contrast to bulk heterojunctions, flat heterojunctions consist of neat organic films, and fortunately, it is possible to sensitize the heterojunctions with additional antenna layers. Efficient energy transfer requires a sufficient overlap between emission of the donor and absorption of the donor as a result of a resonance between the transition dipoles of the involved chromophores. As illustrated in Fig. 1(a), the basic ideas underlying the design of the multiple heterojunction system with antenna effects are: (1) a $p$ - $n$ heterojunction, containing an electron donor ( $p$-conducting) and an acceptor ( $n$-conducting), is photoactive and solely responsible for exciton separation; (2) antenna layers, i.e., energy donors with wide bandgap and large $L_{D}$, are introduced as sensitizers to intensify light absorption and to extend the absorption wavelength range; (3) excitons in the wide-gap antenna layers enter $p$ - or $n$-type layers via efficient energy transfer, and then diffuse to and dissociate at the $p$ - $n$ junction; and (4) according to the transport properties of energy donors, the sensitizer layers shall be located at the respective side of $p-n$ junctions, and adjacent transporting levels of the sensitizer and activator are the prerequisite for charge collection. Therefore, efficient transport and collection of photogenerated charge carriers can be realized, given no significant barriers for holes and/or electrons from the $p-n$ junctions to the energy donors exist. Nevertheless, heterojunctions for effective exciton separation and high mobilities of excitons and charge carriers are essential to achieve highly efficient light- 
a)
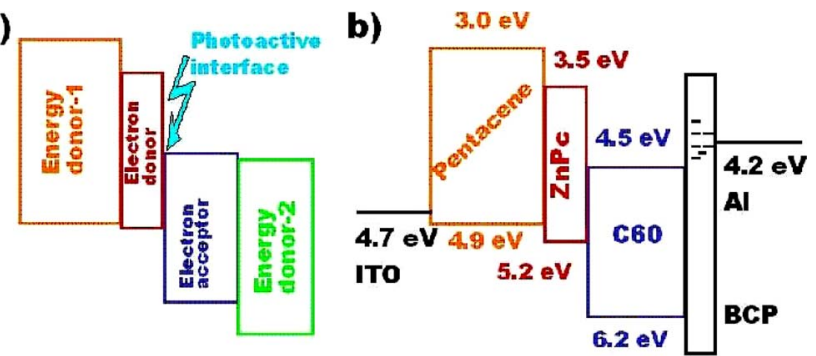

c)

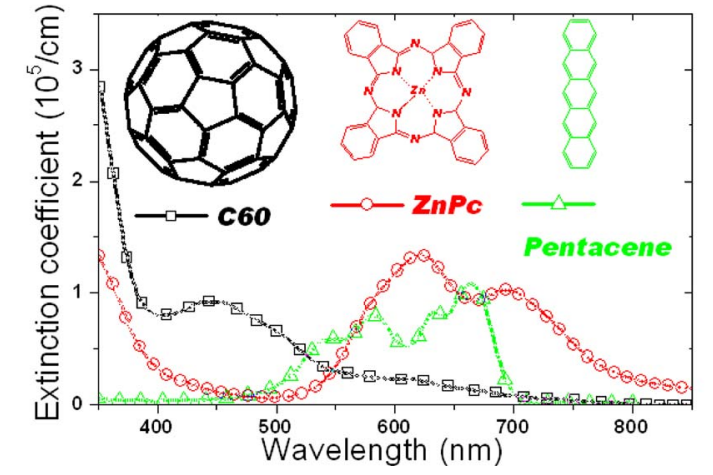

FIG. 1. (Color online) (a) Concept of multiple heterojunction design. (b) Energy diagram of $\mathrm{PV}$ cells based on pentacene $/ \mathrm{ZnPc} / \mathrm{C}_{60}$ multiple heterojunctions. (c) Extinction coefficient curves of the three materials and their molecular structures.

to-electricity conversion, since charge collection by the electrodes is no longer a challenging issue for organic solar cells. ${ }^{6}$

Pentacene $/ \mathrm{C}_{60}$ heterojunctions, which feature high photocurrent $(\mathrm{PC})$ and quantum efficiency, have attracted increasing attention recently. ${ }^{7}$ Excellent hole transport, considerable absorption in wavelength range of $500-700 \mathrm{~nm},{ }^{4}$ and a large exciton diffusion length $\left(L_{D}\right)$ in pentacene films make it promising in future applications for PV cells. Moreover, it has been argued that fission of singlet excitons may occur at a constant rate as high as $10^{13} \mathrm{~s}^{-1}$, and thus generate the double number of triplets, ${ }^{8}$ which could be correlated with the extremely high internal quantum efficiency approaching unity, and suggest the possibility of quantum amplification in organic photonic devices. It is worth noticing that for the typical polyacene series, namely, naphthalene, anthracene, tetracene, and pentacene, as the molecular size and phenyl ring number increase, the $T_{1}$ energy decreases much faster than $S_{1}$, leading to an energy difference of $\sim 1 \mathrm{eV}$ between $S_{1}(\sim 1.9 \mathrm{eV})$ and $T_{1}(\sim 0.9 \mathrm{eV})$ in pentacene. Therefore, $S_{1}$ fission into $2 T_{1}$ could be possible and suggest a great potential of pentacene as a photoactive layer in organic solar cells. Therefore, it is of interest to investigate the origin of photogenerated charge carriers in pentacene $/ \mathrm{C}_{60} \mathrm{PV}$ cells.

The major setback for the PV performance is the low open circuit voltage $\left(V_{\text {oc }}\right)$ determined by the difference between the highest occupied molecular orbital (HOMO) of pentacene and the lowest unoccupied molecular orbital of $\mathrm{C}_{60}{ }^{9}$ It is possible to solve this problem by using other electron acceptors, such as $\mathrm{N}, \mathrm{N}^{\prime}$-ditridecylperylene-3,4,9,10tetracarboxylic diimide. ${ }^{10}$ However, the PC is still lower than the pentacene $/ \mathrm{C}_{60}$ heterojunctions and likely limited by the unbalanced charge carrier mobilities of $p$ - and $n$-type materials.
Zinc phthalocyanine $(\mathrm{ZnPc})$ belongs to a large family of $\mathrm{Pc}$ compounds acting as electron donors in phthalocyanine $/ \mathrm{C}_{60}$ heterojunctions. For this system, the energy levels of the donor and acceptor ensure efficient exciton separation and a moderate open circuit voltage $\left(V_{\mathrm{oc}}\right)$ of $\sim 0.50 \mathrm{~V}$. The strong absorption of $\mathrm{ZnPc}$ in the $600-800 \mathrm{~nm}$ range makes it one of mostly used $p$-type materials for organic solar cells. The bottleneck for efficient exciton separation, however, is the short diffusion length $L_{D}$ in Pcs, which is usually on the order of $10 \mathrm{~nm}$ or less, ${ }^{2}$ much smaller than the thickness necessary for sufficient optical absorption. To circumvent this obstacle, one possible solution is to transfer the excitons from the Pc films to an adjacent matrix with large $L_{D}$ via either resonant or electron-exchange energy transfer processes. With such an antenna effect, the limit imposed by the short $L_{D}$ in Pcs can be removed. More importantly, the structure with antennae possesses enormous flexibility so that maximum effective absorption by locating suitable antenna in accordance with optical intensity distribution in thin film devices can be achieved. Clearly, these advantages have to be balanced versus the energy losses in the transfer processes involved.

In this paper, we present an example that high PC of pentacene $/ \mathrm{C}_{60}$ heterojuctions and high photovoltage of $\mathrm{ZnPc} / \mathrm{C}_{60}$ heterojuctions can be obtained in Pentacene $/ \mathrm{ZnPc} / \mathrm{C}_{60}$ multiheterojunctions as shown in Fig. 1(b). In this system, the $\mathrm{ZnPc} / \mathrm{C}_{60}$ flat heterojunction acts as the photoactive interface where exciton separation occurs. Additionally, excitons from the pentacene layer diffuse to the $\mathrm{ZnPc} / \mathrm{C}_{60}$ interface and are dissociated into free charge carriers. The overall $\mathrm{PC}$ comes from excitons in $\mathrm{ZnPc}$ and $\mathrm{C}_{60}$ films as well as those from pentacene, which is verified by a measurement on external quantum efficiency (EQE), output electron to incident photon, and photoluminescence quenching.

In addition, transient $\mathrm{PC}$ response characteristics are measured, revealing that the triplet excitons are the main origin of free charge carriers in the cells. Taking the triplet exciton energy of $\mathrm{ZnPc}$ and pentacene into account, an endothermic energy transfer process could be a reasonable explanation to the enhanced $\mathrm{PV}$ performance in pentacene $/ \mathrm{ZnPc} / \mathrm{C}_{60}$ multiple heterojunctions. Based on this triplet sensitizing mechanism, a novel design with optimal energy transfer is proposed, in which thin $\mathrm{ZnPc}$ film with $T_{1} \sim 1.1 \mathrm{eV}$ acts as sensitizer in pentacene $\left(T_{1} \sim 0.9 \mathrm{eV}\right)$ bulk layer. Although the sensitizer is located $20 \mathrm{~nm}$ away from the active interface, its contribution to the $\mathrm{PC}$ is observed, confirming the feasibility of the design and offering a promising scheme for wide-range high photoresponse of single cell (with respect to the tandem ones) throughout visible and near infrared.

\section{EXPERIMENTAL}

Materials used are commercially available and purified by vacuum sublimation. PV cells are fabricated on precleaned indium tin oxide (ITO) coated glass substrates by vacuum thermal deposition at a base pressure of $\sim 10^{-5} \mathrm{~Pa}$. Prior to the organic layers, $1 \mathrm{~nm}$ thick the $p$-dopant (either 
2,3,5,6-tetrafluoro-7,7,8,8-tetracyanoquinodimethane

$\left(\mathrm{F}_{4}-\mathrm{TCNQ}\right)$ or NDP2 from Novaled, giving identical results) ${ }^{11}$ is deposited onto ITO substrates to ensure an Ohmic contact between organic active layers and ITO anode. Deposition rates of organic layers and aluminum cathode are 0.5 and $15 \AA / s$, respectively. Cell configurations and corresponding energy level diagram are given in Fig. 1(b). The typical active area of $6.0(2.4 \times 2.5) \mathrm{mm}^{2}$ for each cell is defined by the overlap between ITO anode and aluminum cathode. The devices deposited were then transferred directly to a nitrogen-filled glove-box for characterization without exposure to ambient. The current-voltage $(I-V)$ characteristics are recorded with a source measurement unit (Keithley236). A sun simulator (Hoenle AG) is used as a light source. Different incident light densities are obtained by using neutral filters. The short circuit current $\left(I_{\mathrm{sc}}\right)$ under monochromatic illumination is measured to characterize EQE. The transient behaviors of the encapsulated PV cells are measured with an oscilloscope and a pulse generator. Light pulses of 15-100 ns are used to illuminate cells perpendicularly from the glass substrate side. The pulse width is chosen to be much less than the typical triplet lifetime, and comparable to the RC constants of the cells, which for a load of $50 \Omega$ and a usual capacitance of $\sim 1 \mathrm{nF}$, is $50 \mathrm{~ns}$. Red $(650$ $\mathrm{nm}$ ) light emitting diodes (LEDs) with response time $<100 \mathrm{~ns}$ are used as pulse light sources and monitored by a $\mathrm{Si}$ photodiode. Therefore, the influence of the electrical circuit and cells response on the transient measurement mainly occurs in a time scale of tens of nanoseconds. The LED with spectral bandwidth $<30 \mathrm{~nm}$ is used as a light source to generate excitons mainly in $\mathrm{ZnPc}$ and pentacene, rather than in $\mathrm{C}_{60}$, excluding the influence $\mathrm{C}_{60}$ for simplicity. Absorption and photoluminescence (PL) spectra are measured on spectrometers from Shimadzu and SPEX, respectively. Spectral mismatch between the solar simulator and standard AM 1.5 has minor influence on the conclusions based on parallel comparison, and therefore is not applied to calculation of cell efficiencies.

\section{RESULTS AND DISCUSSION}

\section{A. Pentacene as a sensitizer for $\mathrm{ZnPc} / \mathrm{C}_{60}$ heterojunctions improving PV performance}

Figure 1(b) illustrates a typical PV cell with a multiheterojunction structure. Figure 1(c) shows absorption spectra of the three active materials used in this work, as well as their molecular structures. It is clearly shown that in comparison with the absorption band of $\mathrm{C}_{60}$ ranging from 300 $500 \mathrm{~nm}$, pentacene and $\mathrm{ZnPc}$ have strong absorption mainly

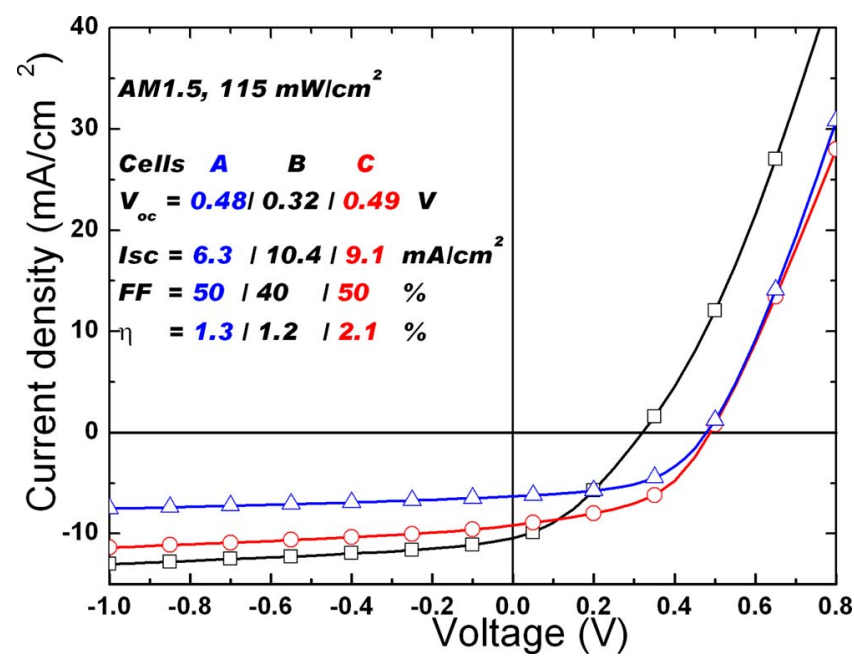

FIG. 2. (Color online) $I-V$ curves of three PV cells under illumination of AM $1.5115 \mathrm{~mW} / \mathrm{cm}^{-2}$, (a) $I T O / N D P 2 / Z n P c(20 \mathrm{~nm}) / \mathrm{C}_{60}(40 \mathrm{~nm}) /$ $\mathrm{BPhen}(8 \mathrm{~nm}) / \mathrm{Al}$, (b) ITO/NDP2/pentacene $(50 \mathrm{~nm}) / \mathrm{C}_{60}(40 \mathrm{~nm}) /$ $\mathrm{BPhen}(8 \mathrm{~nm}) / \mathrm{Al}$, and (c) ITO/NDP2/pentacene $(50 \mathrm{~nm}) / \mathrm{ZnPc}(6 \mathrm{~nm}) /$ $\mathrm{C}_{60}(40 \mathrm{~nm}) / \mathrm{BPhen}(8 \mathrm{~nm}) / \mathrm{Al}$. FF represents fill factor.

in longer wavelength range of 500-800 $\mathrm{nm}$. Pentacene has a bandgap of $\sim 1.9 \mathrm{eV}$, wider than that of $\mathrm{ZnPc}(1.7 \mathrm{eV})$, and both of the two $p$-type materials have adjacent HOMO levels, i.e., HOMO of pentacene is located at $\sim 4.9 \mathrm{eV}$, about $0.3 \mathrm{eV}$ lower than that of $\mathrm{ZnPc}$. This makes exciton diffusion from pentacene to $\mathrm{ZnPc}$ and hole transport in reverse direction energetically possible. The absorption of pentacene films in the red range is weaker than that of $\mathrm{ZnPc}$. However, pentacene film with thickness of $50 \mathrm{~nm}$ can be used as active layers because of large $L_{D}$, therefore, resulting in considerable absorption. Due to these natural advantages, an improved conversion efficiency by inserting a thin $\mathrm{ZnPc}$ film between pentacene and $\mathrm{C}_{60}$ bulk layers is obtained.

Figure 2 shows $I-V$ curves of the two singleheterojunctions and the multiheterojunction in under $\mathrm{AM} 1.5$ $115 \mathrm{~mW} / \mathrm{cm}^{2}$ illumination. Cell $\mathrm{A}$ based on $\mathrm{ZnPc} / \mathrm{C}_{60}$ shows higher $V_{\mathrm{oc}}$ and, however, lower $I_{\mathrm{sc}}$ in comparison with the values of the pentacene $/ \mathrm{C}_{60}$ cell.

It is clear that $V_{\mathrm{oc}}$, as the major drawback for pentacene $/ \mathrm{C}_{60}$ cell (B), dictates the power conversion efficiency $(\eta)$ of $1.2 \%$, a value almost equal to that of the $\mathrm{ZnPc} / \mathrm{C}_{60}$ cell. It is well known that the high $I_{\mathrm{sc}}$ is due to large $L_{D}$ in pentacene. The overall absorption of the cells under 1 sun AM 1.5 illumination can be calculated by optical simulation. The ratio of measured $I_{\mathrm{sc}}$ to the absorption sum of photoactive layers is used as a representative of relative internal quantum efficiencies (IQE), as also shown in Table I.

TABLE I. Summary of PV parameters of the three cells. Each cell has the common parts, i.e., ITO/NDP2 $(1 \mathrm{~nm})$ as the anode contact, and BPhen $(8 \mathrm{~nm}) / \mathrm{Al}$ $(60 \mathrm{~nm})$ on the cathode side. $\tau$ is the PC decay lifetime.

\begin{tabular}{|c|c|c|c|c|c|c|c|}
\hline $\begin{array}{l}\text { Cell structure } \\
(\mathrm{nm})\end{array}$ & $\begin{array}{l}V_{\mathrm{oc}} \\
(\mathrm{V})\end{array}$ & $\begin{array}{c}I_{\mathrm{sc}} \\
\left(\mathrm{mA} \mathrm{cm}^{-2}\right)\end{array}$ & $\mathrm{FF}$ & $\begin{array}{c}\eta_{\mathrm{P}} \\
(\%)\end{array}$ & Saturation factor & $\begin{array}{c}\tau \\
(\mu \mathrm{s})\end{array}$ & RelativeIQE \\
\hline (A) $\mathrm{ZnPc}(20) / \mathrm{C}_{60}(40)$ & 0.48 & 6.33 & 0.51 & 1.3 & 1.18 & 1.39 & 0.80 \\
\hline (B) Pentacene $(50) / \mathrm{C}_{60}(40)$ & 0.32 & 10.40 & 0.40 & 1.2 & 1.23 & 0.80 & 1.68 \\
\hline (C) Pentacene $(50) / \mathrm{ZnPc}(6) / \mathrm{C}_{60}(40)$ & 0.49 & 9.10 & 0.50 & 2.1 & 1.17 & 1.28 & 1.20 \\
\hline (D) Pentacene (25)/ZnPc(3)/pentacen $(25) \mathrm{C}_{60}(40)$ & 0.32 & 9.59 & 0.39 & 1.0 & 1.19 & 1.53 & 1.39 \\
\hline
\end{tabular}




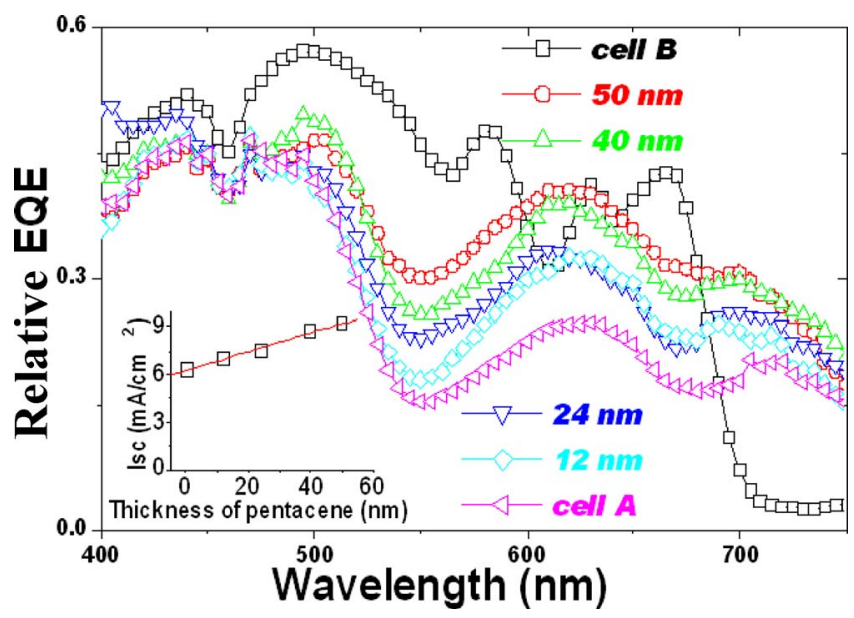

FIG. 3. (Color online) Relative EQE vs wavelength curves of PV cells, ITO/NDP2/pentacene $(X=12,24,40$ and $50 \mathrm{~nm}) / \mathrm{ZnPc}(6 \mathrm{~nm}) /$ $\mathrm{C}_{60}(40 \mathrm{~nm}) / \mathrm{BPhen} / \mathrm{Al}$. Two reference cells, i.e., (a) and (b), are included for comparison.

Cells A and B have relative IQEs of 0.80 and 1.67, respectively. Cell (C) has a moderate value of 1.20. Therefore, for $\mathrm{ZnPc}$ and $\mathrm{C}_{60}$, it is possible to enhance the IQE by circumventing the small $L_{D}$ of $\mathrm{ZnPc}$ via using a multiple heterojunction structure.

In addition to Fig. 2, the main PV parameters of four cells are summarized in Table I. It is obvious that the PV performance of cell $\mathrm{C}$ is determined by the $\mathrm{ZnPc} / \mathrm{C}_{60}$ interface, according to the values of $V_{\text {oc }}$ and fill factor, which are 0.49 and $0.50 \mathrm{~V}$, respectively. The $V_{\mathrm{oc}}$ is slightly higher than cell $\mathrm{A}$, which suggests a higher carrier concentration under the same illumination density due to sensitization effects of pentacene for the $\mathrm{ZnPc}$ interlayer. More importantly, an $I_{\mathrm{sc}}$ of $9.1 \mathrm{~mA} / \mathrm{cm}^{-2}, 40 \%$ higher than the value of $\mathrm{ZnPc} / \mathrm{C}_{60}$ cell, suggests that considerable PC comes from photogenerated excitons in the pentacene film, and that there is no or neglectable energy barrier for hole transfer from $\mathrm{ZnPc}$ to pentacene. Therefore, $\eta$ reaches $2.1 \%$, much higher than for the two single-heterojunction cells, as shown in Table I. The optimal thickness of the $\mathrm{ZnPc}$ interlayer is $6 \mathrm{~nm}$.

Apparently, the sensitization of pentacene to a $\mathrm{ZnPc}$ layer can be asserted from the EQE versus wavelength curves of cells with different pentacene thicknesses. In Fig. 3 , for a fixed thickness of $\mathrm{ZnPc}$ interlayer of $6 \mathrm{~nm}, I_{\mathrm{sc}}$ increases from 6.3 to $9.1 \mathrm{~mA} / \mathrm{cm}^{2}$ for increasing pentacene thickness from 0 to $50 \mathrm{~nm}$, while the $V_{\text {oc }}$ stays constant at $\sim 0.48 \mathrm{~V}$. The inset of Fig. 3 implies a linear increase in $I_{\mathrm{sc}}$ with the thickness of pentacene. According to an optical simulation, the additional pentacene layer only enhances the absorption of $\mathrm{ZnPc}$ layer by $<5 \%$. The major limit to the efficiency of this sensitization process might be the probability of energy transfer from pentacene to $\mathrm{ZnPc}$.

Increasing the $\mathrm{ZnPc}$ thickness above $8 \mathrm{~nm}$ results in a significant loss in PC, suggesting that $L_{D}$ is below this value. On the contrary, thin $\mathrm{ZnPc}$ layers, for example with thickness of 1 and $3 \mathrm{~nm}$ between pentacene and $\mathrm{C}_{60}$, enhance $V_{\mathrm{oc}}$ by several tens of millivolts, which, however, is evidently not enough to compensate the decrease in PC. It is likely that an ultrathin $(<3 \mathrm{~nm}) \mathrm{ZnPc}$ layer is not enough to form a closed layer on the underlying pentacene film. There are two pos-

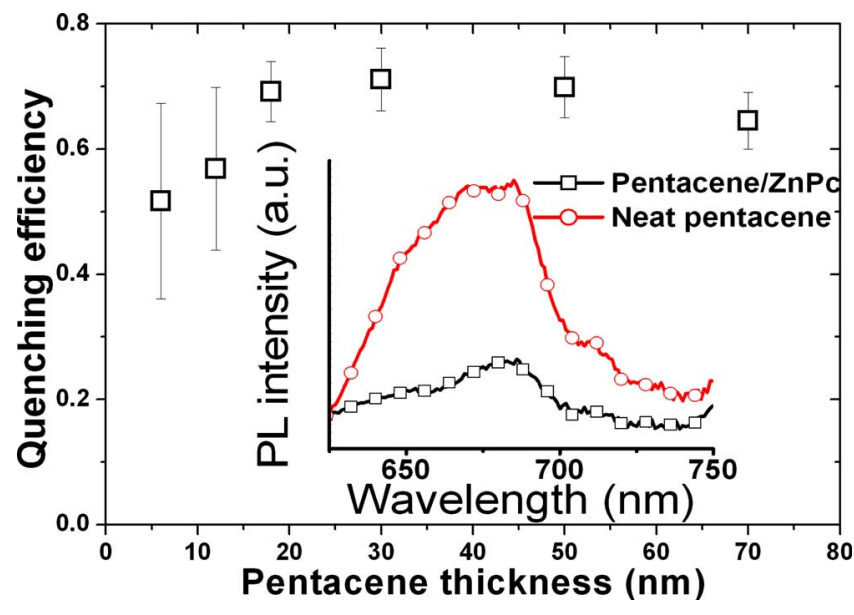

FIG. 4. (Color online) PL quenching efficiency of pentacene films with varied thicknesses in the presence of $6 \mathrm{~nm} \mathrm{ZnPc}$; inset is PL spectra (under excitation of $450 \mathrm{~nm}$ light) of $50 \mathrm{~nm}$ pentacene film with and without $\mathrm{ZnPc}$ quenching layer.

sible reasons for the reduced PC. One is that a threecomponent interface consisting of pentacene, $\mathrm{ZnPc}$, and $\mathrm{C}_{60}$ is not as efficient as a simple DA heterojunction for exciton separation. Since two donor materials contact statistically with $\mathrm{C}_{60}$, the local potential distribution might not be as uniform and thus inefficient for exciton separation compared to a simple single heterojunction. The second reason is the enhanced charge carrier recombination induced by the islandlike $\mathrm{ZnPc}$ layer, which may introduce defect sites as recombination centers and induces exciton quenching. With our experimental approach, it was not possible to further clarify this question.

It is worth noticing that, while preparing the present manuscript, a similar device structure with $2 \mathrm{~nm} \mathrm{ZnPc}$ film between pentacene and $\mathrm{C}_{60}$, published by Kinoshita et al., ${ }^{12}$ shows improvement in both $I_{\mathrm{sc}}$ and $V_{\mathrm{oc}}$, without sacrificing FF. More recently, Sista et al. ${ }^{13}$ independently reported enhancement in $V_{\text {oc }}$ through a cascade-type energy band structure based on an asymmetric pentacene derivative, copper $\mathrm{Pc}$, and $\mathrm{C}_{60}$. Considerable sensitization effects of copper PC by a pentacene derivative are observed. In our case, the optimum thickness of the $\mathrm{ZnPc}$ interlayer in terms of PV performance is slightly larger, most likely due to different growth modes of $\mathrm{ZnPc}$ interlayers on pentacene, which depend strongly on experimental conditions.

\section{B. Photoluminescence quenching measurements}

To better understand the mechanisms of the multiple heterojunction, PL quenching effects of $\mathrm{ZnPc}$ on pentacene films with various thicknesses are also measured. As shown in Fig. 3 inset, the PL emission of pentacene film under 450 $\mathrm{nm}$ light excitation at room temperature peaks at $680 \mathrm{~nm}$, which corresponds to radiative transitions of $S_{1}$ excitons. ${ }^{14}$ With an additional thin $\mathrm{ZnPc}$ layer on the films (Note here that thickness of $\mathrm{ZnPc}$ quenching layer is too small to induce significant optical interference; thus absorption changes in the pentacene layer can be neglected), a PL quenching of $\sim 70 \%$ is observed from pentacene films with varied thicknesses, i.e., 10-70 nm (Fig. 4). The weak PL of neat penta- 
cene film implies that nonradiative decay is dominating the relaxation of $S_{1}$, consistent with a large intersystem crossing rate of $\sim 10^{13} \mathrm{~s}^{-1}$ (Ref. 8). The spectral overlap between absorption and PL emission of pentacene film results in serious self-absorption and strong interaction of excitons with ground state molecules. This suggests that the photogenerated $S_{1}$ excitons can hardly be converted into PC in either pentacene $/ \mathrm{C}_{60}$ simple heterojunctions or pentacene $/ \mathrm{ZnPc} / \mathrm{C}_{60}$ multiple heterojunctions.

Assuming that $S_{1}$ excitons, rather than triplets, in pentacene layer contribute to the $\mathrm{PC}$ in both pentacene $/ \mathrm{C}_{60}$ and pentacene $/ \mathrm{ZnPc} / \mathrm{C}_{60}$ heterojunctions, and that $70 \%$ of $S_{1}$ excitons diffuse into the $\mathrm{ZnPc}$ interlayer, the $\mathrm{PC}$ of the optimal pentacene $/ \mathrm{ZnPc} / \mathrm{C}_{60}$ cell may reach $12.0 \mathrm{~mA} / \mathrm{cm}^{2}$ estimated from optical simulation, even higher than the pentacene $/ \mathrm{C}_{60}$ cell. The real $\mathrm{PC}$ value is only $9.1 \mathrm{~mA} / \mathrm{cm}^{2}$, suggesting $S$-S energy transfer from pentacene to $\mathrm{ZnPc}$ is not the major energetic process in the multiply heterojunction cells. This difference then leads to the question on the origin of the PC, which is discussed in Sec. C.

\section{Origin of the PC}

To verify the origin of the PC in the PV cells, transient $\mathrm{PC}$ response over a time scale from $10^{-9} \mathrm{~s}$ to $10^{-3} \mathrm{~s}$ is measured. It is known that singlet-to-triplet intersystem crossing takes place in $\mathrm{C}_{60}$ (Ref. 15) and $\mathrm{ZnPc}$ (Ref. 16) with high quantum yield. In flat heterojunctions, $L_{D}$ is recognized to be extremely important in photon-to-electron conversion. That is, diffusion coefficient and lifetime of excitons shall be as large as possible. In this sense, photoactive materials with strong intersystem crossing from $S_{1}$ to $T_{1}$ have the advantage of long exciton lifetime and are hence preferable candidates for organic PV cells. 17

In flat heterojunctions, ideally, free charge carriers generated by exciton separation at the DA interface diffuse into the neat $p$ or $n$-type layers, and recombination losses can be neglected. Providing high mobilities well above $10^{-3} \mathrm{~cm}^{2} \mathrm{v}^{-1} \mathrm{~s}^{-1}$, the lifetime of charge carriers is no longer important for their extraction. The following experiment and conclusions are based on this argument. Recent reports ${ }^{18}$ on transient PC in polymer bulk heterojunctions show long and nonexponential decays of several to tens microseconds. This can be attributed to relatively low mobility and considerable carrier recombination in polymer blends, involving germinate recombination, recapture of carriers by their counterparts, thus also leading to a long effective lifetime of the charge carriers.

The PC response curves of several cells are shown in Fig. 5. All cells have similar decay lifetimes $(\tau)$ on the order of $1 \mu \mathrm{s}$, as also summarized in Table I. The PC versus time nearly follows a single exponential decay over several microseconds. Under normal light intensity, interaction of exciton with excitons and charge carriers in the photoactive layers is negligible. The single exponential decay curves imply that the triplets in the active layers are the main element contributing to the PC. Again, if charge transport process is decisive, the diffusion current being the main component of PC should follow a double exponential profile. ${ }^{19}$ A close in-

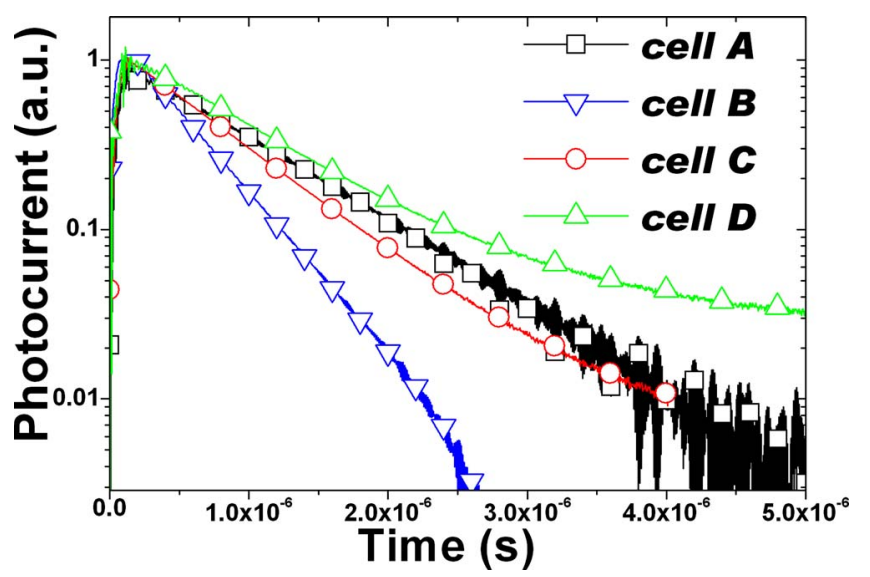

FIG. 5. (Color online) PC transients of the PV cells.

spection of the initial stage of the decay curves shows no fast-decaying components immediately after the incident light is cut off, again proving that the major part of the PC results from triplet excitons, not singlets. The PC decay time of about $1 \mu \mathrm{s}$ is obviously shorter than the reported values of $T_{1}$ lifetime in $\mathrm{C}_{60}$ and $\mathrm{ZnPc}$, which are usually on the order of $100 \mu \mathrm{s}$. For pentacene, it is still unknown to our best knowledge. In comparison with the neat films, the interface where ultrafast charge transfer occurs can be regarded as a two-dimensional plane with unity quenching efficiency. Since the PC response curves follow the decay behavior of $T_{1}$ excitons within the diffusion length $L_{D}$, the charge transfer process shortens the $T_{1}$ lifetime by introducing a nonradiative decay channel, which becomes dominant in the relaxation process. In a precise measurement of $L_{D}$ done by Markov et al., ${ }^{20}$ a time-dependent lifetime is introduced to explain the nonexponential PL decay of polymer films of thicknesses much larger than $L_{D}$ in the presence of a quencher layer. In our case, only the $T_{1}$ states that diffuse to the interface can be detected and converted to PC signals. The opposite acceptor or donor film imposes another quenching constant via charge transfer effects, in addition to radiative and nonradiative relaxation in the neat layer, resulting in the single exponential decay.

Among the cells $\mathrm{A}, \mathrm{B}$, and $\mathrm{C}$ with single exponential decay curves, the single pentacene $/ \mathrm{C}_{60}$ heterojunction has a $\tau$ of $0.80 \mu \mathrm{s}$, which could be due to the superior exciton mobility in pentacene. $\tau$ of cells $\mathrm{A}$ and $\mathrm{C}$ are 1.38 and $1.29 \mu \mathrm{s}$, suggesting the dominant role of the $\mathrm{ZnPc} / \mathrm{C}_{60}$ interface in both cells.

The long PC decay indicates that triplet excitons in pentacene have some probability to diffuse into the $\mathrm{ZnPc}$ layer, meaning that endothermic energy transfer occurs. Although exothermic energy transfer from $\mathrm{ZnPc}$ to pentacene should be an energetically favorable process, according to the improved $\mathrm{PC}$ in cell $\mathrm{C}$ compared to cell $\mathrm{A}$, it is not a competitive decay channel for $T_{1}$ in $\mathrm{ZnPc}$, in comparison with the efficient interface-induced charge transfer. We suppose that the lifetime of $T_{1}$ excitons in a neat $\mathrm{ZnPc}$ layer is shortened in the presence of a $\mathrm{ZnPc} / \mathrm{C}_{60}$ interface, and thus the efficiency of $\mathrm{ZnPc}$-to-pentacene triplet energy transfer is reduced. 


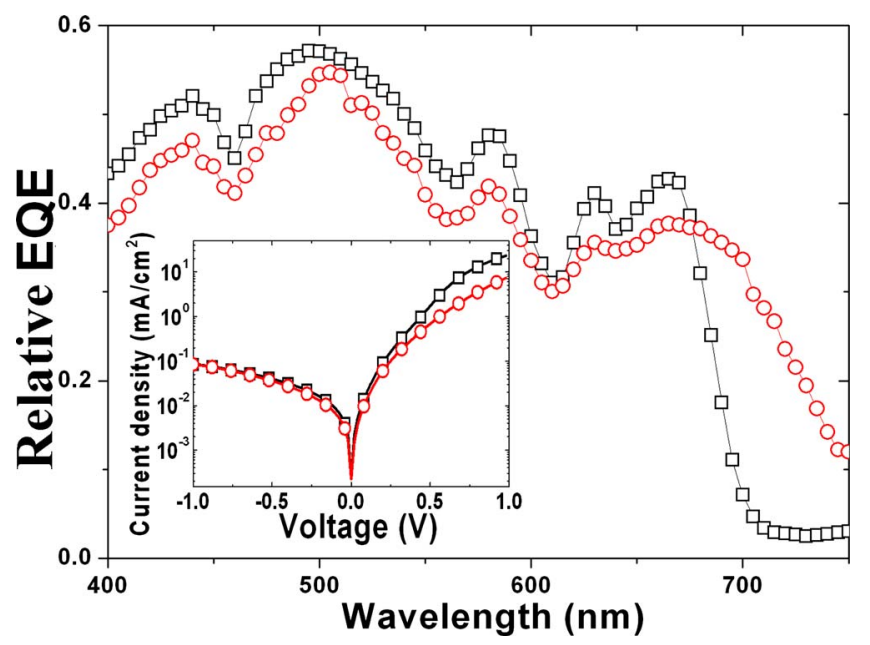

FIG. 6. (Color online) Relative EQE vs wavelength curves of PV cells (b) and (d), showing enhancement effects of EQE in the wavelength range over $680 \mathrm{~nm}$ by introducing ultrathin layer of $\mathrm{ZnPc}$ sensitizer in the pentacene bulk layer.

The exothermic triplet diffusion from $\mathrm{ZnPc}$ to pentacene leads to another possible structure of $\mathrm{ITO} / \mathrm{ZnPc} /$ pentacene $/ \mathrm{C}_{60} / \mathrm{BPhen} / \mathrm{Al}$. The inferior PV performance (not shown) indicates that the significant hole transport barrier from pentacene to $\mathrm{ZnPc}$ layers prevents hole collection.

\section{D. $\mathrm{ZnPc}$ as a sensitizer to extend the photoresponse of pentacene $/ \mathrm{C}_{60}$ heterojunctions}

In view of the participation of triplet excitons in pentacene films, another type of design based on antenna effects is proposed: $\mathrm{PV}$ cells in which a $\mathrm{ZnPc}$ sensitizing layer is embedded in pentacene bulk layer are presented. PV cell $\mathrm{D}$ with a structure of ITO/pentacene $(25 \mathrm{~nm}) / \mathrm{ZnPc}(3 \mathrm{~nm}) /$ pentacene $(25 \mathrm{~nm}) / \mathrm{C}_{60}(40 \mathrm{~nm}) / \operatorname{BPhen}(8 \mathrm{~nm}) / \operatorname{Al}(10 \mathrm{~nm})$ is also used to confirm the main role that triplet excitons play in the multiple heterojunctions. With a $T_{1}$ of $\sim 1.1 \mathrm{eV}$ in $\mathrm{ZnPc}$ and $\sim 0.9 \mathrm{eV}$ in pentacene, exciton diffusion from $\mathrm{ZnPc}$ to pentacene is an energetically favorable process. Since the HOMO level of $\mathrm{ZnPc}$ is deeper than that of pentacene, the insertion of an ultrathin $\mathrm{ZnPc}$ film in the pentacene layer does not impose any hole traps, but results in a noncontinuous hole blocking layer. When the $\mathrm{ZnPc}$ layer is too thin to form a uniform film, the hole blocking effects are less important and efficient hole transport in the whole pentacene layer is still possible. In cell D, a $3 \mathrm{~nm} \mathrm{ZnPc} \mathrm{layer} \mathrm{is} \mathrm{used} \mathrm{to}$ ensure sufficient absorption, although it increases series resistance and lowers the EQE from 400 to $600 \mathrm{~nm}$ as shown in Fig. 6. Compared to the reference cell $\mathrm{B}$ without $\mathrm{ZnPc}$ sensitizor, $\mathrm{EQE}$ in the longer wavelength range is obviously enhanced by inserting the $\mathrm{ZnPc}$ layer. The $\mathrm{EQE}$ profile of the reference cell follows the absorption of pentacene, which has a cutoff edge at around $700 \mathrm{~nm}$. Cell D has almost same $\mathrm{EQE}$ value at $625 \mathrm{~nm}$, and even higher than the reference cell beyond $680 \mathrm{~nm}$. It is evident that the ultrathin $\mathrm{ZnPc}$ layer behaves as an antenna for pentacene $/ \mathrm{C}_{60}$ heterojunctions (HJs), due to strong absorption of $\mathrm{ZnPc}$ in long wavelength range as shown in Fig. 1. Because of the larger optical gap of pentacene compared to $\mathrm{ZnPc}$, as well as quenching effects of
$\mathrm{ZnPc}$ on PL of pentacene, the enhanced $\mathrm{EQE}$ at long wavelength can be definitely attributed to triplets in $\mathrm{ZnPc}$, which apparently enter pentacene layer via exothermic energy transfer.

On the other hand, the PC decay curve of cell D deviates from single exponential, showing a multicomponent decay process. The long tail associated to a slow decay process could be a hint for energy exchange between $\mathrm{ZnPc}$ and pentacene via triplets, i.e., energy transfer in both direction occurs and slows down the PC decay.

\section{CONCLUSIONS}

Multiple heterojunctions consisting of three photoactive materials in single PV cells have been proven to be effective due to enhanced absorption intensity and extended wavelength range. As a result, an improved power conversion efficiency of $2.1 \%$, being more than $50 \%$ higher than the respective single heterojunction cells, is obtained. PC transient of PV cells suggests that $T_{1}$ states in $\mathrm{ZnPc}$ and pentacene mainly contribute to PC. A new design based on $T-T$ energy transfer is proposed and tested experimentally.

\section{ACKNOWLEDGMENTS}

Z.H. gratefully acknowledges the Alexander von Humboldt Foundation for financial support, and thanks T. Mueller, T. H. Ke, and R. Schueppel for valuable discussions. R.L. acknowledges CAPES/Brazil for a scholarship. This work was supported by the DFG via the Leibniz prize.

${ }^{1}$ C. W. Tang, Appl. Phys. Lett. 48, 183 (1986).

${ }^{2}$ P. Peumans, A. Yakimov, and S. R. Forrest, J. Appl. Phys. 93, 3693 (2003).

${ }^{3}$ J. Y. Kim, K. Lee, N. E. Coates, D. Moses, T. Q. Nguyen, M. Dante, and A. J. Heeger, Science 317, 222 (2007).

${ }^{4}$ R. Koeppe, O. Bossart, G. Calzaferre, and N. S. Sariciftci, Sol. Energy Mater. Sol. Cells 91, 986 (2007).

${ }^{5}$ Y. X. Liu, M. A. Summers, C. Edder, J. M. J. Frechet, and M. D. McGehee, Adv. Mater. (Weinheim, Ger.) 17, 2960 (2005).

${ }^{6}$ M. Y. Chan, S. L. Lai, K. M. Lau, C. S. Lee, and S. T. Lee, Appl. Phys. Lett. 89, 163515 (2006).

${ }^{7}$ S. Yoo, B. Domercq, and B. Kippelen, Appl. Phys. Lett. 85, 5427 (2004). ${ }^{8}$ C. Jundt, G. Klein, B. Sipp, J. Le Moigne, M. Joucla, and A. A. Vellaeys, Chem. Phys. Lett. 241, 84 (1995).

${ }^{9}$ C. J. Brabec, A. Cravino, D. Meissner, N. S. Sariciftci, M. T. Rispens, L. Sanchez, J. C. Hummelen, and T. Fromherz, Thin Solid Films 403-404, 368 (2002)

${ }^{10}$ A. K. Pandey, S. Dabos-Seignon, and J. M. Nunzi, Appl. Phys. Lett. 89, 113506 (2006)

${ }^{11}$ Z. R. Hong, B. Maennig, R. Lessmann, M. Pfeiffer, K. Leo, and P. Simon, Appl. Phys. Lett. 90, 203505 (2007).

${ }^{12}$ Y. Kinoshita, T. Hasobe, and H. Murata, Appl. Phys. Lett. 91, 083518 (2007).

${ }^{13}$ S. Sista, Y. Yao, Y. Yang, M. L. Tang, and Z. Bao, Appl. Phys. Lett. 91, 223508 (2007)

${ }^{14}$ R. He, N. G. Tassi, G. B. Blanchet, and G. Pinczuk, Appl. Phys. Lett. 87, 103107 (2005).

${ }^{15}$ J. W. Arbogast, A. P. Darmanyan, C. S. Foote, Y. Rubin, F. N. Diederich, M. M. Alvarez, S. J. Anz, and R. L. Whetten, J. Phys. Chem. 95, 11 (1991).

${ }^{16}$ X. F. Zhang and H. J. Xu, J. Chem. Soc., Faraday Trans. 89, 3347 (1993).

${ }^{17}$ Y. Shao and Y. Yang, Adv. Mater. (Weinheim, Ger.) 17, 2841 (2005).

${ }^{18}$ T. Offermans, S. C. J. Meskers, and R. A. J. Janssen, J. Appl. Phys. 100, 074509 (2006)

${ }^{19}$ P. W. Blom, V. D. Mihailetchi, L. J. A. Koster, and D. E. Markov, Adv. Mater. (Weinheim, Ger.) 19, 1551 (2007).

${ }^{20}$ D. E. Markov, J. C. Hummelen, P. W. Blom, and A. B. Sieval, Phys. Rev. B 72, 045216 (2005). 